\title{
Effect of Empiric Antiarrhythmic Therapy in Resuscitated Out-of-Hospital Cardiac Arrest Victims with Coronary Artery Disease
}

\author{
Ali R. Moosvi, MD, Sidney Goldstein, MD, Sharon VanderBrug Medendorp, MPH, \\ J. Richard Landis, PhD, Robert A. Wolfe, PhD, Richard Leighton, MD, \\ George Ritter, MD, C. Mark Vasu, MD, and Allyn Acheson
}

\begin{abstract}
The effect of emplicic antiarthythmic therapy with quinidine and procalnamide on long-term mortally was examined in 209 patients wth coronary artery disease resuscltated after out-of-hospital cardlac arrest. The antiarrhythmic agent used was delermined by the patient's private physiclan without knowlodge of the study ambulatory eloctrocardiogram. Of the 209 patients, procalnarnide was prescribed in $45(22 \%)$, quinidine in $48(23 \%)$ and no antlarnhythmic therapy in 116 (55\%). Digoxin therapy was initiated in 101 patients. The 2-year total survival rate for the quinldine, procainamide and nontreated patients was 61, 57 and $71 \%(p$ $<0.05$ ), and for sudden doath was 69,69 and $89 \%$ $(p<0.01)$, respectively. These observations surgest that empiric antiarnhythmic therapy in survivors of out-of-hospital cardiac arrest did not affect total mortallty and was associated with an increased frequency of sudden death.
\end{abstract}

(Am J Cardlol 1990;65:1192-1197)

From the Henry Ford Heart and Vascular Institute, Department of Medicine, Division of Cardiovascular Medicine, Henry Ford Hospital, Detroit, and the Department of Biostatistics, University of Michigan, Ann Arbor, Michigan. This study was supported in part by grant HL188000-09 from the National Heart, Lung, and Blood Institute, Bethesda, Maryland, and the EMS Foundation of Grand Rapids, Michigan. Manuscript received August 30, 1989; revised manuscript received and accepted January 8, 1990.

Address for reprints: Sidney Goldstein, MD, Henry Ford Hospital, Division of Cardiovascular Medicine, 2799 West Grand Boulevard, Detroit, Michigan 48202.
$\mathrm{T}$ he efficacy of antiarrhythmic agents in patients with cardiovascular disease is currently being reevaluated in the light of new clinical data. ${ }^{1} \mathrm{Al}$ though these drugs are effective in suppressing ventricular arrhythmias, they have not been shown to prolong life in a randomized controlled trial. The recent reports of the Cardiac Arrhythmia Suppression Trial indicate that certain drugs may actually be associated with an accelerated mortality despite their ability to suppress ventricular ectopy. Victims resuscitated after out-ofhospital cardiac arrest are known to be at an increased risk of another cardiac arrest. Frequent ventricular ectopy is known to be a characteristic of these patients, 2,3 and it is presumed that treatment with antiarrhythmic agents may have a salutary effect on their mortality rate. Several studies in patients with frequent ventricular ectopy using a variety of antiarrhythmic agents with and without electrophysiologic guidance report a decrease in mortality rate when compared to historical controls. ${ }^{4-6}$

In a previous report by us, the most significant clinical predictor of total mortality in this group of resuscitated out-of-hospital survivors was a history of digoxin therapy; for sudden death it was quinidine therapy. ${ }^{3}$ Frequent and repetitive ventricular ectopy was also demonstrated to be predictive of total mortality in this population. ${ }^{7}$ The increased mortality rate associated with digoxin and quinidine therapy was thought to be due either to the adverse effect of the drugs or to the presence of heart failure for which digoxin therapy could be considered a surrogate. This study retrospectively compares the effect of empiric therapy with quinidine, procainamide or placebo, with and without concurrent digoxin therapy, on survival in patients who have been resuscitated after an out-of-hospital cardiac arrest.

\section{METHODS}

This is a retrospective analysis of the effect of empiric antiarrhythmic therapy in previously reported patients resuscitated after out-of-hospital cardiac arrest ${ }^{3}$ from July 1, 1975, through June 30, 1982. Informed consent was obtained and eligible patients were registered. Laboratory and electrocardiographic data were collected. Hospital and Emergency Medical Service records were reviewed for clinical information relating to medical history. Because study ambulatory electrocardiographic data were not available at the time of dis- 
charge or at any time during the follow-up, the medical management of patients in regard to treatment of cardiac failure and arrhythmias was determined by each patient's private physician without regard to this information.

The patients were classified using previously described methodology. ${ }^{3}$ Of the 274 patients successfully resuscitated, $227(83 \%)$ were classified as having significant coronary heart disease, based on the presence of a previous myocardial infarction, angina pectoris or coronary angiographic evidence of significant coronary arterial obstruction. Of these 227 patients, complete data regarding digoxin and antiarrhythmic drug therapy were available in 209 (76\%) patients. This group of 209 patients is the population analyzed in this study. Eightysix $(41 \%)$ of these patients were classified as having an acute myocardial infarction, $79(38 \%)$ an ischemic event and $44(21 \%)$ primary arrhythmic events. Patients were interviewed by the study nurse 2 months after discharge, and every 4 months thereafter. After each visit the clinical status of the patient was evaluated and compliance for all medication was established.

Death within 1 hour of new or accelerating symptoms was classified as sudden death. The follow-up period ranged from a minimum of 6 months to a maximum of 93 months with an average of 35 months. Quinidine was prescribed as quinidine gluconate or sulfate 3 to 4 times daily for a total average dose of $1.14 \mathrm{~g}$ (range 0.6 to 2.6). The average daily dose of procainamide was 2.0 g (range 0.75 to 3.0 ) administered every 4 to 6 hours. Digoxin was prescribed in a dose of 0.125 or $0.25 \mathrm{mg}$. Blood concentrations of the drugs were not obtained.

The cumulative mortality graphs for antiarrhythmic agents were based on assignment of antiarrhythmic
FiQURE 1. Cumulative total survival for the study population.
FIGURE 2. Cumulattre wodden death survival for the study population.
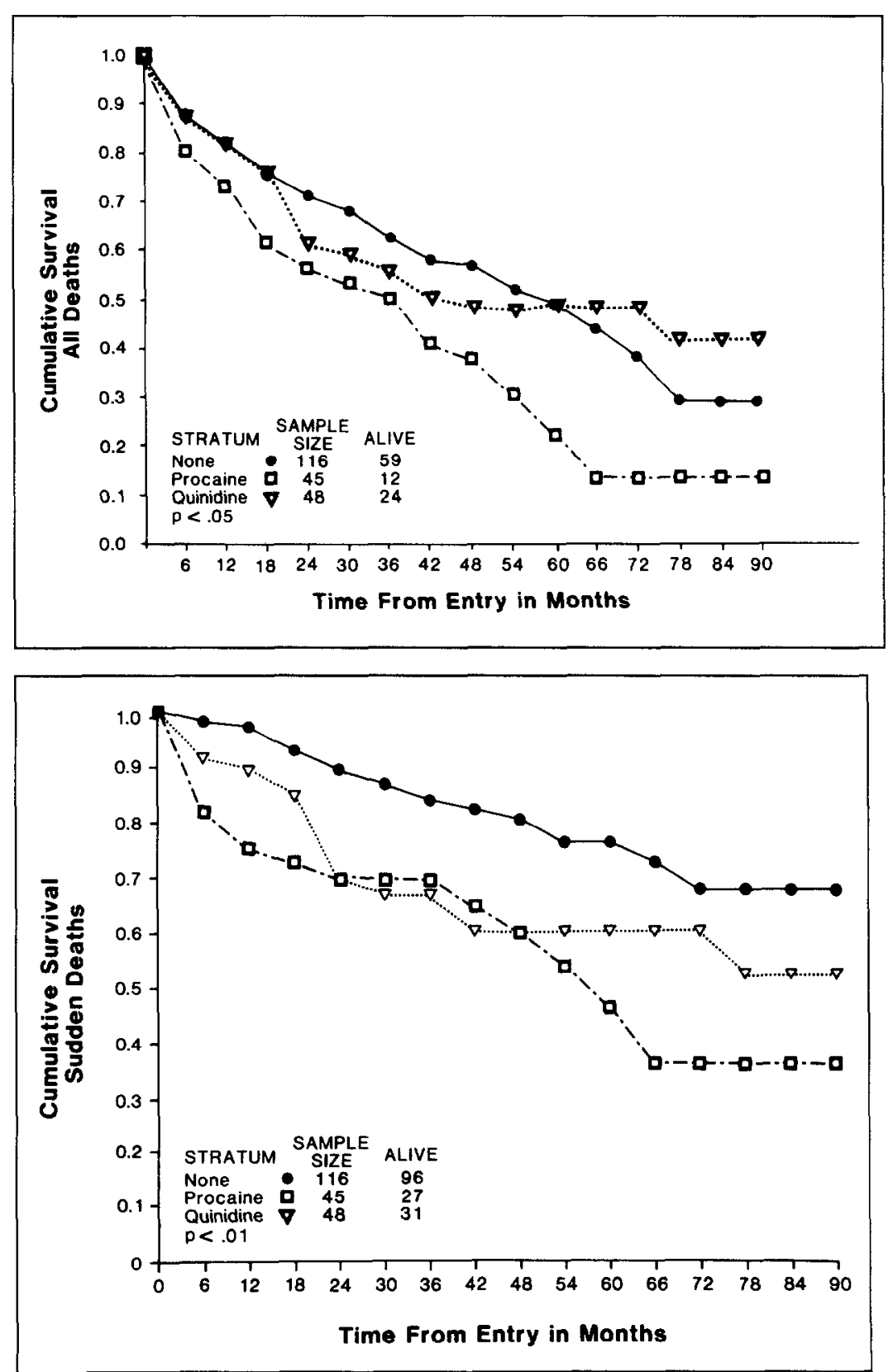
drug at the time of discharge. The survival distributions of the 3 treatment groups overall and within digoxin status categories were calculated using the product-limit method and compared using the log rank test. 8.9 The Cox-Breslow life table procedure, as implemented in the BMDP series, was used to examine the importance of possible covariates. ${ }^{10}$

\section{RESULTS}

Characteristics of study patients are listed in Table I. Patients were classified at the time of discharge into 6 groups based on the prescription of quinidine and procainamide and whether or not digoxin therapy was used in each of these groups.

When the patients prescribed digoxin were compared to those who were not, a significant $(p<0.001)$ difference was observed in some factors. Patients pre- scribed digoxin were older ( 65 vs 60 years), and had an increased incidence of previous myocardial infarction, pulmonary congestion and diuretic intake. The antiarrhythmic prescription, however, was not significantly different. At the 3-month follow-up visit, $96.4 \%$ of those prescribed quinidine and $92.3 \%$ of those prescribed procainamide were still taking their original drug. At 6 months, $76.7 \%$ and $78.6 \%$, respectively, of patients continued with their initial drug therapy.

When concomitant digoxin therapy was disregarded, cumulative total (Figure 1) and sudden death (Figure 2) survival rates were significantly lower for patients treated with procainamide and quinidine, compared to those who did not receive these drugs. The 2-year cumulative total survival rates (Figure 1) for quinidine, procainamide and no therapy were 61,57 and $71 \%$, respectively $(p<0.05)$. The 2 -year sudden death survival

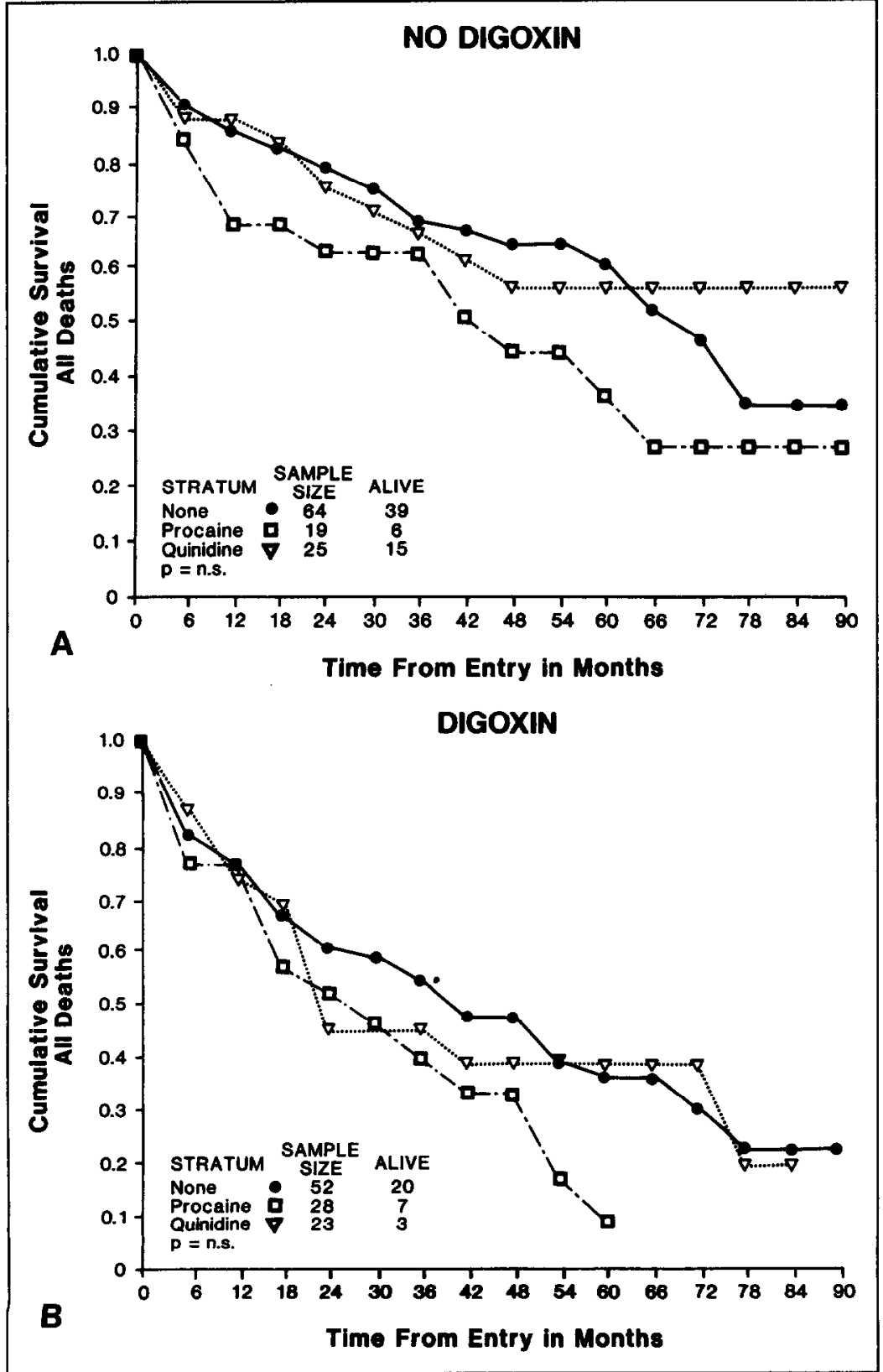

FIGURE 3. Cumulative total sarvival in patients not receiving digoxh $(A)$ and those recelving digoxin (B). 
rates (Figure 2) for the quinidine, procainamide and no therapy groups were 69,69 and $89 \%$, respectively (p $<0.01$ ).

The effect of the concomitant use of digoxin with the antiarrhythmic agents on the total survival was not associated with a statistically significant difference between the 3 antiarrhythmic treatment groups (Figure 3 ). Patients receiving digoxin, however, generally had a worse total survival rate. The 2-year cumulative survival rates for quinidine, procainamide and no therapy groups in patients not receiving digoxin (Figure 3A) were 75, 63 and $79 \%$, respectively $(p=0.16)$, and in patients receiving digoxin (Figure $3 \mathrm{~B}$ ) were 43,51 and $61 \%$, respectively $(\mathrm{p}=0.19)$.

When sudden death survival (Figure 4) was examined, both quinidine- and procainamide-treated patients experienced a worse sudden death survival rate com- pared to the no treatment group, regardless of concurrent digoxin therapy. The 2-year sudden death survival rates for quinidine, procainamide and no therapy groups in patients not receiving digoxin (Figure 4A) were 79, 63 and $91 \%$, respectively $(\mathrm{p}<0.05$ ), and in patients receiving digoxin were 57,76 and $88 \%$, respectively ( $\mathrm{p}$ $<0.05)$.

While the relation of digoxin and antiarrhythmic therapy to worse survival seems clear when examined univariately, given the design of the study and the mechanism for assigning treatment, it is possible that they are not the only predictors of survival. This is indicated by the association of digoxin therapy with various other factors such as age and previous myocardial infarction (Table I). Using a stepwise model building procedure, the predictive value of age, previous myocardial infarction and pulmonary congestion, along with digox-
FIGURE 4. Cumulative sudden death survival for patients not receiving digoxin (A) and those recelving digoxin (B).

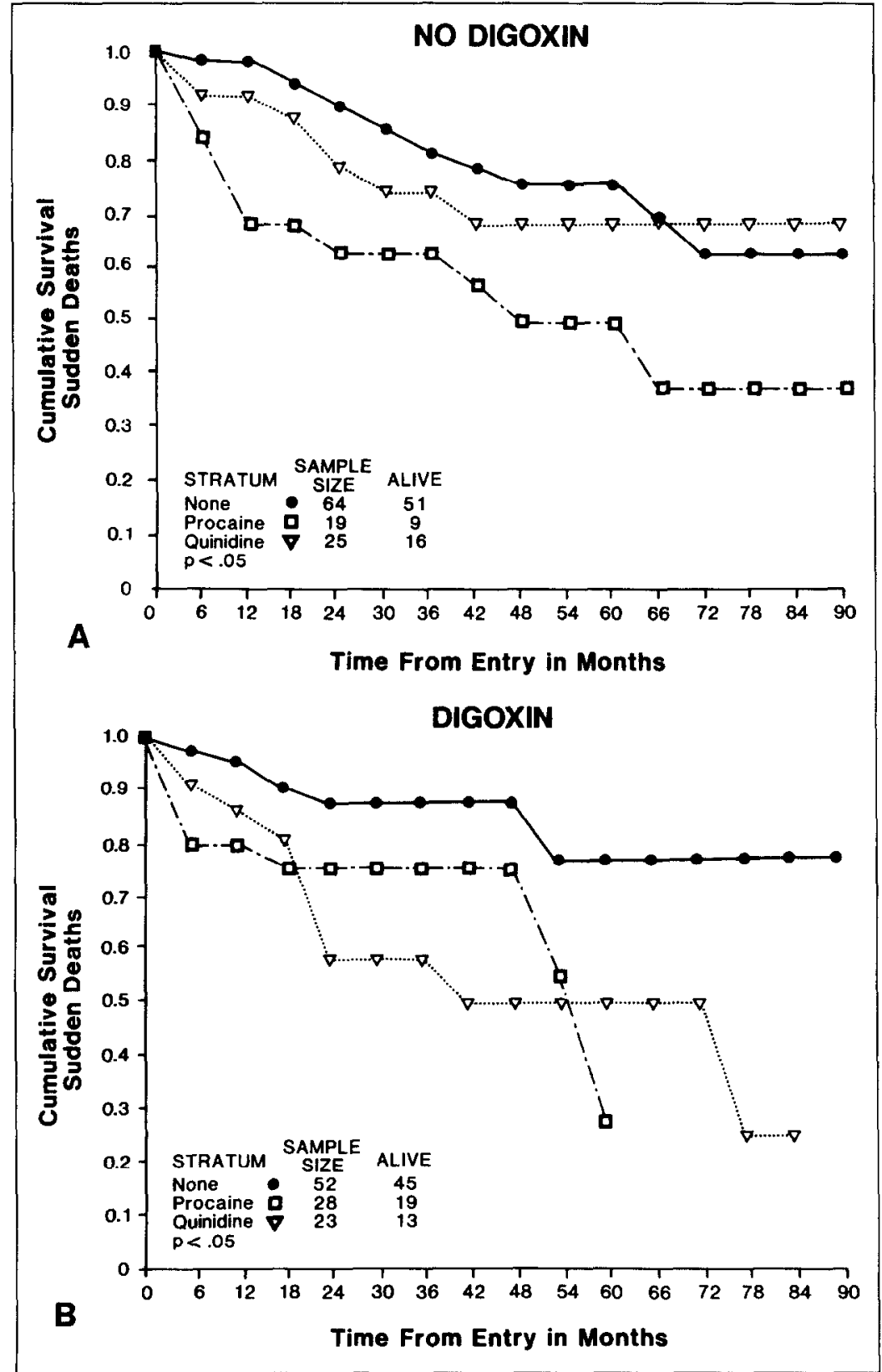




\begin{tabular}{|c|c|c|c|c|c|c|c|c|}
\hline & \multicolumn{4}{|c|}{ No Digoxin } & \multicolumn{4}{|l|}{ Digoxin } \\
\hline & $\begin{array}{l}\text { None } \\
(n=64)\end{array}$ & $\begin{array}{l}P \\
(n=19)\end{array}$ & $\begin{array}{l}Q \\
(n=25)\end{array}$ & $\begin{array}{l}\text { Both } \\
(n=108)\end{array}$ & $\begin{array}{l}\text { None } \\
(n=52)\end{array}$ & $\begin{array}{l}P \\
(n=26)\end{array}$ & $\begin{array}{l}Q \\
(n=23)\end{array}$ & $\begin{array}{l}\text { Both } \\
(n=101)\end{array}$ \\
\hline Mean age (yrs) & 59 & 59 & 61 & $60^{*}$ & 65 & 66 & 62 & $65^{*}$ \\
\hline \multicolumn{9}{|l|}{ History (\%) } \\
\hline Angina & 47 & 74 & 60 & 55 & 52 & 77 & 65 & 61 \\
\hline Heart failure & 72 & 58 & 52 & $65^{*}$ & 89 & 85 & 70 & $83^{*}$ \\
\hline Hypertension & 47 & 37 & 36 & 43 & 60 & 54 & 52 & 56 \\
\hline Previous MI & 25 & 63 & 36 & $34^{*}$ & 58 & 77 & 65 & $64^{*}$ \\
\hline \multicolumn{9}{|l|}{ Hospital course (\%) } \\
\hline Acute MI & 50 & 37 & 40 & 45 & 42 & 19 & 44 & 37 \\
\hline $\mathrm{PC}$ & 55 & 32 & 32 & 45 & 77 & 65 & 70 & 72 \\
\hline \multicolumn{9}{|c|}{ Medications at discharge (\%) } \\
\hline Other antiarrhythmics & 0 & 5 & 0 & 1 & 0 & 0 & 4 & 1 \\
\hline Diuretics & 19 & 21 & 16 & $19^{*}$ & 69 & 65 & 57 & $65^{*}$ \\
\hline Propranolol & 13 & 5 & 4 & 9 & 12 & 0 & 0 & 6 \\
\hline
\end{tabular}

in and antiarrhythmic status, was considered for both overall survival and sudden death survival. The strongest predictors of death were age and previous myocardial infarction, while the strongest predictors for sudden death were age, treatment with an antiarrhythmic agent and previous myocardial infarction. These results indicate that antiarrhythmic therapy is related to worse survival. However, with this study design it is difficult to determine if the poorer survival is related to the antiarrhythmic drug itself or to additional factors.

\section{Discussion}

It must be emphasized that this is a retrospective analysis of a very unique patient population in whom antiarrhythmic agents were administered empirically. It is not a randomized, controlled study of antiarrhythmic therapy in this population. Nevertheless, it does raise some important issues in regard to therapy of this high risk population. The choice of antiarrhythmic therapy was made by the practicing physician, who was unaware of the results of the ambulatory electrocardiogram. It is possible that physicians identified the high risk patient by other clinical characteristics and therefore chose to initiate antiarrhythmic therapy. This could explain the higher mortality rate observed in the patients prescribed antiarrhythmic therapy. With the exception of baseline differences in patients receiving digoxin, there were no consistent differences in regard to the administration of antiarrhythmic agents. The prescribed dosage of quinidine and procainamide was in the usual dose range and drug compliance is consistent with other antiarrhythmic trials. We observed in this analysis that patients who received no therapy appeared to fare the best, although this reached statistical significance only in the sudden death group.

Our previous examination of predictors of death in resuscitated out-of-hospital cardiac arrest victims indicated that the history of digoxin therapy is associated with worse survival rate. ${ }^{3}$ This observation suggested that heart failure was a significant predictor of subsequent death, and this has been supported by others. ${ }^{111-13}$ However, digoxin therapy, left ventricular dysfunction and ventricular ectopy are so closely interrelated that it is difficult to isolate the importance of each of these factors. ${ }^{13,14}$ The present analysis indicates that the use of digoxin was one of a number of multivariate predictors associated with an overall decreased total survival rate.

Antiarrhythmic therapy in patients resuscitated after a cardiac arrest has been generally considered advisable, if not mandatory, since a high frequency of ventricular arrhythmia is associated with an accelerated mortality rate. ${ }^{3,7}$ The suggestion that antiarrhythmic therapy can be of benefit in this population has come from uncontrolled drug therapy directed by ambulatory electrocardiography or electrophysiologic studies. Using serial ambulatory electrocardiographic monitoring, the use of multiple antiarrhythmic agents in high risk patients appeared to show a decreased mortality compared to historical controls. ${ }^{4} \mathrm{~A}$ major confounding variable, however, is the association of ventricular ectopy with left ventricular dysfunction. Arrhythmia suppression and the associated risks of therapy are adversely influenced by a decreased ejection fraction. 1,17,18 The Cardiac Arrhythmia Suppression Trial examined the effect of arrhythmia suppression on sudden death mortality. ${ }^{1} \mathrm{En}$ cainide and flecainide arms of the study were prematurely stopped when an increased rate of arrhythmic death and total mortality was observed with those drugs compared to placebo. The sudden death rate at 1 year for patients with ejection fractions $<30 \%$ was $9.5 \%$ with drugs and $3.6 \%$ with placebo. In patients with ejection fractions $>30 \%$, it was $3.7 \%$ and $0.8 \%$, respectively.

Balanced against the uncertain benefits of antiarrhythmic therapy are the well-documented proarrhythmic effects of a number of these agents. ${ }^{11,19-22}$ Adverse reaction to antiarrhythmic agents is adversely affected by digoxin and diuretic therapy..$^{19}$ These events are presumed to occur early after the institution of drug therapy, and were observed with almost all of the currently 
available agents. ${ }^{21}$ There was a tendency in this study for an accelerated mortality early after initiation of therapy but the survival curves continued to fall throughout the follow-up period, which is similar to the observations of the Cardiac Arrhythmia Suppression Trial.

Although our data are applicable to a very unique group of patients with coronary artery disease, they also have important implications for patients with coronary artery disease in general, and they are consistent with recent studies. ${ }^{1}$ Our present observations suggest that empiric antiarrhythmic therapy with quinidine and procainamide fails to provide protection in this high risk group. In each survival analysis, the patients who did not receive an antiarrhythmic agent fared better than those who were treated with these drugs, although this was statistically significant only in regard to sudden death. These observations should give us pause before embarking on empiric antiarrhythmic therapy in this high risk population.

\section{REFERENCES}

1. The Cardiac Arrhythmia Suppression Trial (CAST) Investigators. Preliminary report: effect of encainide and flecainide on mortality in a randomized trial of arrhythmia suppression after myocardial infarction. $N$ Engl $J$ Med 1989;321: $406-412$.

2. Weaver W, Cobb L, Hallstrom A. Ambulatory arrhythmias in resuscitated victims of cardiac arrest. Circulation 1982,66:212-218.

3. Goldstein S, Landis JR. Leighton R, Ritter G. Vasu CM, Wolfe RA, Acheson A, Medendorp SV. Predictive survival models for resuscitated victims of out-ofhospital cardiac arrest with coronary artery disease. Circulation 1985:71:873880 .

4. Graboys TB, Lown B, Podrid P. Long term survival of patients with malignant ventricular arrhythmias treated with antiarrhythmic drugs. Am J Cardiol 1982;50:437-443

5. Wilber DJ, Garan H, Finkelstein D, Kelly E, Newell J, McGovern B, Ruskin JN. Out-of-hospital cardiac arrest: use of electrophysiologic testing in the prediction of long-term outcome. $N$ Engl J Med 1988;318:19-24.
6. Josephson ME, Horowitz LW, Spielman SR, Greenspan AM. Electrophysiologic and hemodynamic studies in patients resuscitated from cardiac arrest. Am J Cardiol 1980;46:948-955.

7. Temesy-Armos PN, Vanderbrug Medendorp S, Goldstein S, Landis JR, Leighton RF, Ritter G, Vasu CM, Wolfe RA, Acheson A. Predictive value of ventricular arrhythmias in resuscitated out-of-hospital cardiac arrest victims. Eur Heart $J$ 1988.9:625-633.

8. Kaplan EL, Meir P. Nonparametric estimation from incomplete observations. J Am Stat Assoc 1958;53:457-481.

9. Peto R. Peto J. Asymptotically efficient rank invariant test procedures. $J R$ Stat Soc [A] 1972,135:185-198.

10. Hopkins A. Survival analysis with covariates-Cox models. In: Dixon WJ, ed. BMDP Statistical Software. Berkeley, California: University of California Press, 1983:576.

11. Swerdlow CD, Winkle RA, Mason JW. Determinants of survival in patients with ventricular tachyarrhythmias. $N$ Engl J Med 1983:308:1436-1442.

12. Moss AJ, Davis HT, Conrad DL, DeCamilla JJ, Odoroff CL. Digitalisassociated cardiac mortality after myocardial infarction. Circulation 1981. 64:1150-1156.

13. Multicenter Postinfarction Research Group. Risk stratification after myocardial infarction. $N$ Engl $J$ Med 1983;309:33I-336.

14. Byington $R$, Goldstein $S$. Association of digitalis therapy with mortality in survivors of acute myocardial infarction: observations in the Beta-Blocker Heart Attack Trial. JACC 1985:5:976-982.

15. Peter T, Hamer A, Weiss D, Mandel WJ. Prognosis after sudden cardiac death without associated myocardial infarction: one year follow-up of empiric therapy with amiodarone. Am Heart J 1984;107:209-213.

16. Rapaport $E$, Remedios $P$. The high risk patient after recovery from myocardial infarction: recognition and management. JACC 1983;1:391-400.

17. Meissner MD, Kay HR, Horowitz LN, Spielman SR, Greenspan AM, Kutalek SP. Relation of acute antiarrhythmic drug efficacy to left ventricular function in coronary artery disease. Am J Cardiol 1988.61:1050-1055.

18. Pratt CM, Eaton $T$, Francis $M$, Woolbert $S$, Mahmarian $J$, Roberts $R$, Young JB. The inverse relationship between baseline left ventricular ejection fraction and outcome of antiarrhythmic therapy: a dangerous imbalance in the risk-benefit ratio. Am Heart $J$ 1989;118:433-440.

19. Minardo JD, Heger JJ, Miles WM, Zipes DP, Prystowsky EN. Clinica characteristics of patients with ventricular fibrillation during antiarrhythmic drug therapy. $N$ Engl I Med 1988:319:257-262.

20. Podrid PJ, Lampert S, Grayboys TB, Blatt CM, Lown B. Aggravation of arrhythmia by antiarrhythmic drugs-incidence and predictors. Am $J$ Cardiol 1987:59:38E-44E.

21. Stanton MS, Prystowsky EN, Fineberg NS, Miles WM, Zipies DP, Heger JJ. Arrhythmogenic effects of antiarrhythmic drugs: a study of 506 patients treated for ventricular tachycardia or fibrillation. JACC 1989;14:209-215.

22. Velebit V, Podrid P, Lown B, Cohen BH, Graboys TB. Aggravation and provocation of ventricular arrhythmias by antiarrhythmic drugs. Circulation $1982,65: 886-894$. 